\title{
Diffusion of mineral acids into an epoxy coating. Phosphoric acid diffusion model
}

\author{
V.A. Golovin, (1)* A.B. Il'in and A.D. Aliev \\ A.N. Frumkin Institute of Physical Chemistry and Electrochemistry, Russian Academy \\ of Sciences, Leninskii pr. 31, 119071 Moscow, Russian Federation \\ *E-mail: golovin@rocor.ru
}

\begin{abstract}
A series of studies on the diffusion and sorption of phosphoric acid solutions with concentrations of $54-87 \mathrm{wt} \%$ into epoxy coating materials was carried out. Local X-ray analysis and luminescence analysis were used to determine the penetration depths and to plot concentration profiles of diffusion penetration of several mineral acids. It was shown that in the case of phosphoric acid, in contrast to hydrochloric and sulfuric acids, a significant gradient of diffusant concentration was observed in the diffusion zone, and the distribution profile in the diffusion zone had indications of a 2-step structure. The diffusion data obtained and the results of thermodynamic calculations were used to determine the parameters of the diffusion penetration model with partial chemical binding of the penetrating acid. The diffusion model with hydrates of constant composition $\left(\mathrm{H}_{3} \mathrm{PO}_{4} \cdot n \mathrm{H}_{2} \mathrm{O}\right.$, where $\left.n=10-11\right)$ in the inner solution was shown to describe correctly $\left(R^{2}=0.9986\right)$ the kinetics of the penetration of concentrated solutions of phosphoric acid. The use of the diffusion model combined with a calculation of the chemical potential of non-volatile electrolytes based on the Gibbs-Duhem equation makes it possible to significantly reduce the amount of diffusion studies and simplify the prediction of the impermeability time of coating materials in highly corrosive media, including nonvolatile ones.
\end{abstract}

Keywords: epoxy coatings, phosphoric acid, concentration profile, diffusion model, GibbsDuhem equation, hydrate number, fluorescence spectrum, phosphorescence time.

Received: October 14, 2021. Published: November 17, 2021

doi: $\underline{10.17675 / 2305-6894-2020-10-4-13}$

\section{Introduction}

Polymeric coatings based on thermosetting plastics are widely used for anticorrosion protection of inner equipment surfaces in acid media. Positive experience has been gained in the use of multilayered epoxy coatings in hydrochloric and sulfuric acids [1] and phenol heat-curable coatings in phosphoric acid and its mixtures with other mineral acids [2].

As temperature and concentration increase, the service life of polymer coatings shortens considerably due to acceleration of acid penetration. In view of this, estimation of the resource of a polymer coating in acids, especially at enhanced temperatures, should be primarily based on studying the penetration of the corrosive medium into polymer materials and developing a phenomenological temperature-concentration diffusion model. Such a model [3] takes into account the mutual effect of both the thermodynamic activity of acid 
and activity of water in the inner solution on the diffusion transport. The model was shown to be correct for hydrochloric acid in the entire concentration range and, for sulfuric acid, up to a concentration of $40 \%$ and a temperature of up to $70^{\circ} \mathrm{C}$, i.e., in the non-oxidizing range. The model also predicts the shape of concentration profiles and the rate of acid front penetration for hydrochloric, sulfuric, and a number of organic acids.

It was reported $[4,5]$ that the diffusion profiles of polybasic phosphorus-containing acids are close qualitatively to those of $\mathrm{HCl}, \mathrm{H}_{2} \mathrm{SO}_{4}$, and organic acids. However, there is a lack of systematic data for widely used phosphoric acid, including the high-concentration region that is of utmost practical interest. As a result, there is no experimentally tested model that would enable the prediction of diffusion impenetrability of coatings based on thermosetting plastics for phosphoric acid.

\section{Goal of the study}

This study aims at exploring the regularities of diffusion penetration of phosphoric acid into polymer epoxy coatings by recording diffusion profiles in a wide concentration range at elevated temperature to test the models of phosphoric acid diffusion into epoxy anticorrosion materials.

\section{Study objects}

We studied model epoxy formulations based on ED-20 diane resin (TU (technical requirements) 2225-114-07510508-2013) with amine-based curing agents: aliphatic triethylenetetramine TETA (TU 6-02-1099-83) and polyethylenepolyamine PEPA (TU 413646-11131395-2007); and aromatic - meta-phenylenediamine MPDA (GOST 5826-78); amine-based plasticizing modifier and accelerator with catalytic activity RAO-20; and elasticizer based on butadiene-acrylonitrile carboxylated rubber SKN-26-1A (TU 38.30301-41-92). Coating materials were heated from $+20^{\circ} \mathrm{C}$ to $+120^{\circ} \mathrm{C}$ at $20^{\circ} \mathrm{C}$ steps and kept for $12 \mathrm{~h}$ at the maximum temperature.

\section{Experimental techniques}

The diffusion profile of penetrating acids was primarily recorded using X-ray fluorescence that occurs under the impact of the electron beam in an electron microscope, along with optical fluorescence induced by ultraviolet and visible range photons in a laser fluorescence microscope [3]. To minimize distortions in the distribution of acids, samples were primarily prepared using transverse cleavage-and-cut of the surface.

Since the operating conditions of the electron microscope required that the polymer samples be maintained in a deep vacuum, possible desorption of volatile diffusants, such as $\mathrm{HCl}$, from the surface layers of the sample was always taken into account. This effect is especially likely if the depth of medium penetration into the polymer is small and the medium solubility in the polymer is low. This may result in both qualitative and quantitative distortions of the concentration profile shape and emergence of systematic errors. This 
implies that the results with a large penetration depth obtained upon long exposure in a corrosive media are the most reliable. However, preliminary results have shown that the distortion of the diffusion profiles of low-volatile and non-volatile acids, including phosphoric acid, is insignificant at various evacuation times.

The validity of data on the penetration of acids was additionally checked using fluorescence microscopy that does not require evacuation. This allows one to observe the intensity profile and polymer fluorescence spectra for both non-volatile $\mathrm{H}_{3} \mathrm{PO}_{4}$ or lowvolatile $\mathrm{H}_{2} \mathrm{SO}_{4}$, volatile acids such as $\mathrm{HCl}$ and organic acids, dichlorethane, dimethylsulphoxide, and other organic diffusants. Optical fluorescence spectra also enable the assessment of specific features of chemical reactions between the reactive groups of polymers and acid anions [6]. Earlier studies [3] have shown that acid penetration depths determined by both methods are virtually identical.

Combining the two scanning methods for studying the surfaces of samples makes it possible to obtain information about the rate, diffusion profile of acid distribution, diffusant solubility in the polymer, and specific features of the chemical reaction between acid anions and reactive groups of the polymer.

Local X-ray spectral analysis (LXSA) enables the quantitative determination of the concentration distribution of characteristic elements such as chlorine $\mathrm{Cl}$, sulfur $\mathrm{S}$, and phosphorus $\mathrm{P}$ contained in $\mathrm{HCl}, \mathrm{H}_{2} \mathrm{SO}_{4}$, and $\mathrm{H}_{3} \mathrm{PO}_{4}$, respectively. The sorption of acids in epoxy samples was estimated from the maximum concentration of the characteristic elements.

LXSA was carried out according to technique [7] using a JSM-U3 electron microscope with an energy dispersive X-ray spectrometer and GETAC digital scanning adapter. GETAC software performs ZAF correction for the standardless calculation of the content of elements. An LiSi semiconductor detector with an ultrathin polymer window and a resolution of $140 \mathrm{eV}$ was used.

Fluorescence studies were conducted using a LUMAM-IZ microscope with a photometric FMEL-1 attachment (FEU-39A for measurements in the blue-green part of the spectrum and FEU-79 for measurements in the red part of the spectrum) and an Altami LUM-1-LED microscope in the excitation/observation ranges: UV (ultraviolet) 250$290 \mathrm{~nm} / 330-400 \mathrm{~nm}, \quad \mathrm{~V}$ (violet-blue) $395-415 \mathrm{~nm} / 420-500 \mathrm{~nm}, \quad B \quad$ (blue) 420 $485 \mathrm{~nm} / 480-700 \mathrm{~nm}$ and $\mathrm{G}$ (green) $460-550 \mathrm{~nm} / 600-700 \mathrm{~nm}$. To record the fluorescence profile during the penetration of acids, the fluorescence spectral microprobe technique was used [3]. The image capturing devices were controlled and data were analyzed and processed using the Altami Studio certified program. 


\section{Experimental results}

5.1. Comparison of the diffusion profiles of $\mathrm{HCl}, \mathrm{H}_{2} \mathrm{SO}_{4}$, and $\mathrm{H}_{3} \mathrm{PO}_{4}$ obtained by local X-ray spectral analysis

As noted above, detection of diffusion profiles is the most informative technique among diffusion/sorption studies of polymer coatings in acid solutions, since the kinetics and shape of the profile movement into the polymer depth provides information about the solubility of the acid in the polymer containing reactive groups and sequential development stages of the diffusion process.

We consider the results of local X-ray spectral analysis for three acids that are most widely used in industry, i.e., hydrochloric, sulfuric, and phosphoric acids.

Figure 1 below shows the distribution profiles of the characteristic elements in these acids: hydrochloric acid (chlorine $\mathrm{Cl}$ ), sulfuric acid (sulfur $\mathrm{S}$ ), and phosphoric acid (phosphorus $\mathrm{P}$ ) detected in the course of bidirectional diffusion of $\mathrm{HCl}, \mathrm{H}_{2} \mathrm{SO}_{4}$, and $\mathrm{H}_{3} \mathrm{PO}_{4}$ solutions into sheet-like samples of the model epoxy-based material. The mineral acids under study differ both in basicity (mono-, di-, and tribasic acid, respectively) and oxidizing capacity (sulfuric acid is an expressed oxidizer, while hydrochloric and phosphoric acids are not oxidizers).

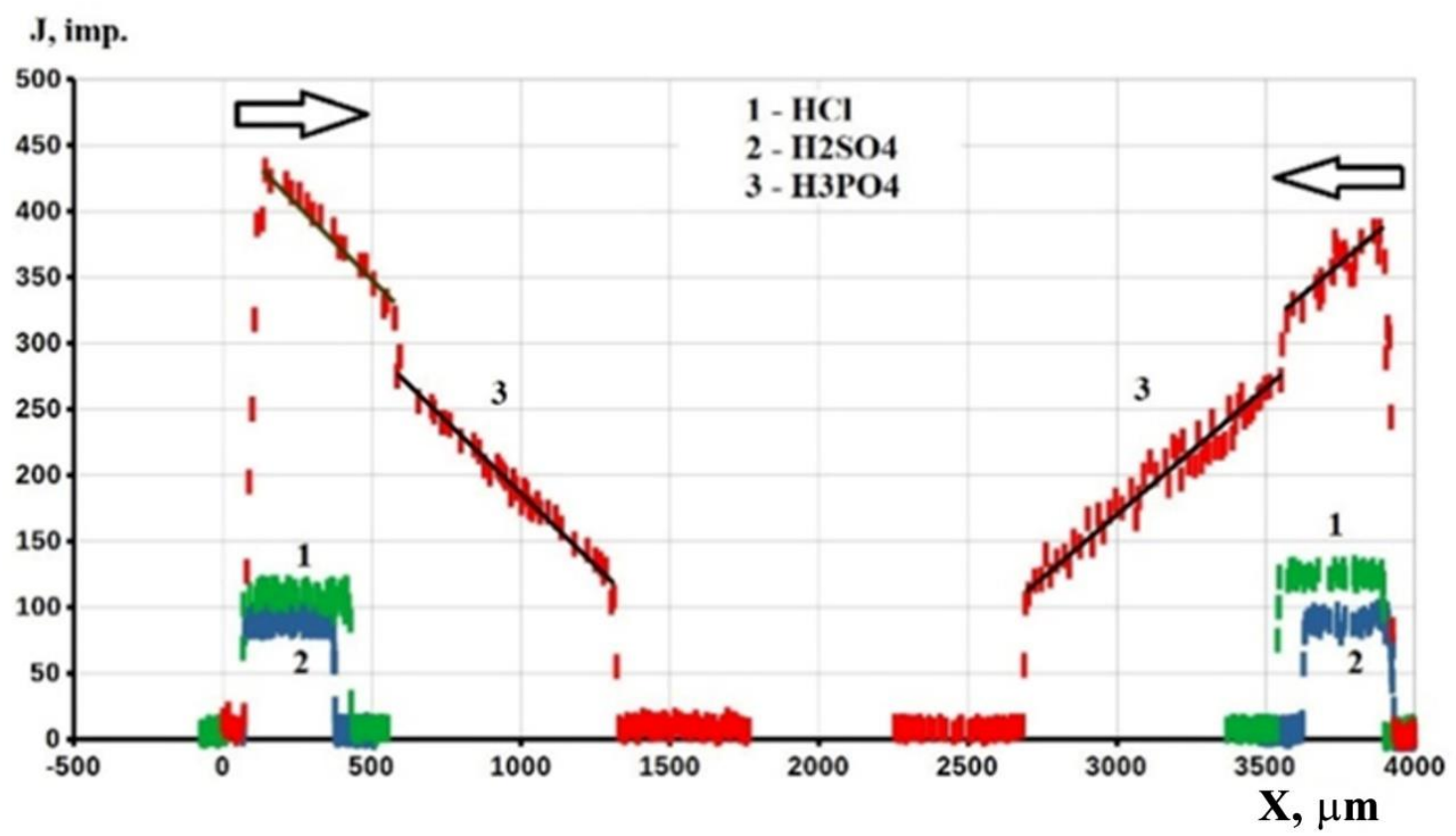

Figure 1. Bidirectional diffusion profiles of the characteristic elements: 1 -chlorine $\mathrm{Cl}$ (green), 2 -sulfur S (blue), 3-phosphorus $\mathrm{P}$ (red) in the penetration of $20 \% \mathrm{HCl}, 40 \% \mathrm{H}_{2} \mathrm{SO}_{4}$ and $60 \%$ $\mathrm{H}_{3} \mathrm{PO}_{4}$, respectively, at $50^{\circ} \mathrm{C}$ for $\mathrm{t}=1008 \mathrm{~h}$ into a model epoxy-based material with an aminebased hardener. Composition: ED-20-100 mass parts; SKN-26-1A - 5 mass parts; and TETA - 10 mass parts (based on stoichiometry). Arrows show the direction of the diffusion of acids. 
The results presented show that the concentration profiles of the penetration of acids into a polymer exhibit both common and individual regularities:

- all acids feature a non-Fickian diffusion profile characterized by a very steep step-like boundary between the acid penetration zone and internal polymer layers where acids are not detected;

- hydrochloric and sulfuric acids feature a concentration profile close to a П-shaped one with an insignificant diffusant concentration gradient in the diffusion zone from the sample surface to the steep diffusion boundary. Such a profile shape is predicted by the theoretical model [3] in which the diffusants are rapidly bound at the steep penetration boundary. This implies that transport actually occurs across the polymer matrix chemically modified by an acid;

- in contrast to hydrochloric and sulfuric acid, phosphoric acid exhibits a significant gradient of diffusant concentration; the distribution profile in the diffusion zone has the features of a 2-step structure. Such a phosphoric acid profile can be explained by a more complex mechanism of binding of phosphate anions with charges 1,2 , and 3 , with residual functional groups of the amine-cured epoxy polymer.

\subsection{Effect of additives to the polymer on the diffusion of phosphoric acid}

Certain conclusions regarding the mechanism of the emergence of a 2-step profile can be drawn based on the analysis of diffusant distribution profiles upon variation of the polymermatrix composition, in particular, by varying the amount of the amine-based curing agent to levels higher and lower than the stoichiometric value and assessing the effect of the plasticizers on the glassy state of the cross-linked matrix.

For example, addition of an amine-based curing agent to the system in amounts larger or smaller than the stoichiometric value changes the number of acid binding centers and the ratio of amino groups with various degrees of conversion, and thus alters the process of chemical biding of the acid by the polymer.

The profile shape can also be affected by the glass-like state of the matrix that is plastisized by liquid nitrile rubber SKN-26-1A or, additionally, by the RAO-20 elasticizer. Due to the amine nature of the RAO-20 additive, its addition also changes the content of amino groups in the polymer.

Figure 2 shows a comparison of the diffusion profiles of phosphoric acid penetration into a formulation with a stoichiometric amount of the curing agent (profile 1) and epoxybased formulations with addition of an increased (profile 2) and decreased (profile 3) amount of the amine-based curing agent.

The conclusion may be drawn that the widely used additives to epoxy compounds such as amine-based elasticizing/curing agents fail to significantly change the overall shape of the profiles that preserve two zones in the diffusion area. The concentration/solubility and penetration velocity of the diffusion front of phosphoric acid changes significantly but regularly: with a decrease in the amine content the penetration depth diminishes, while with an increase in the content and elastification, it increases. 


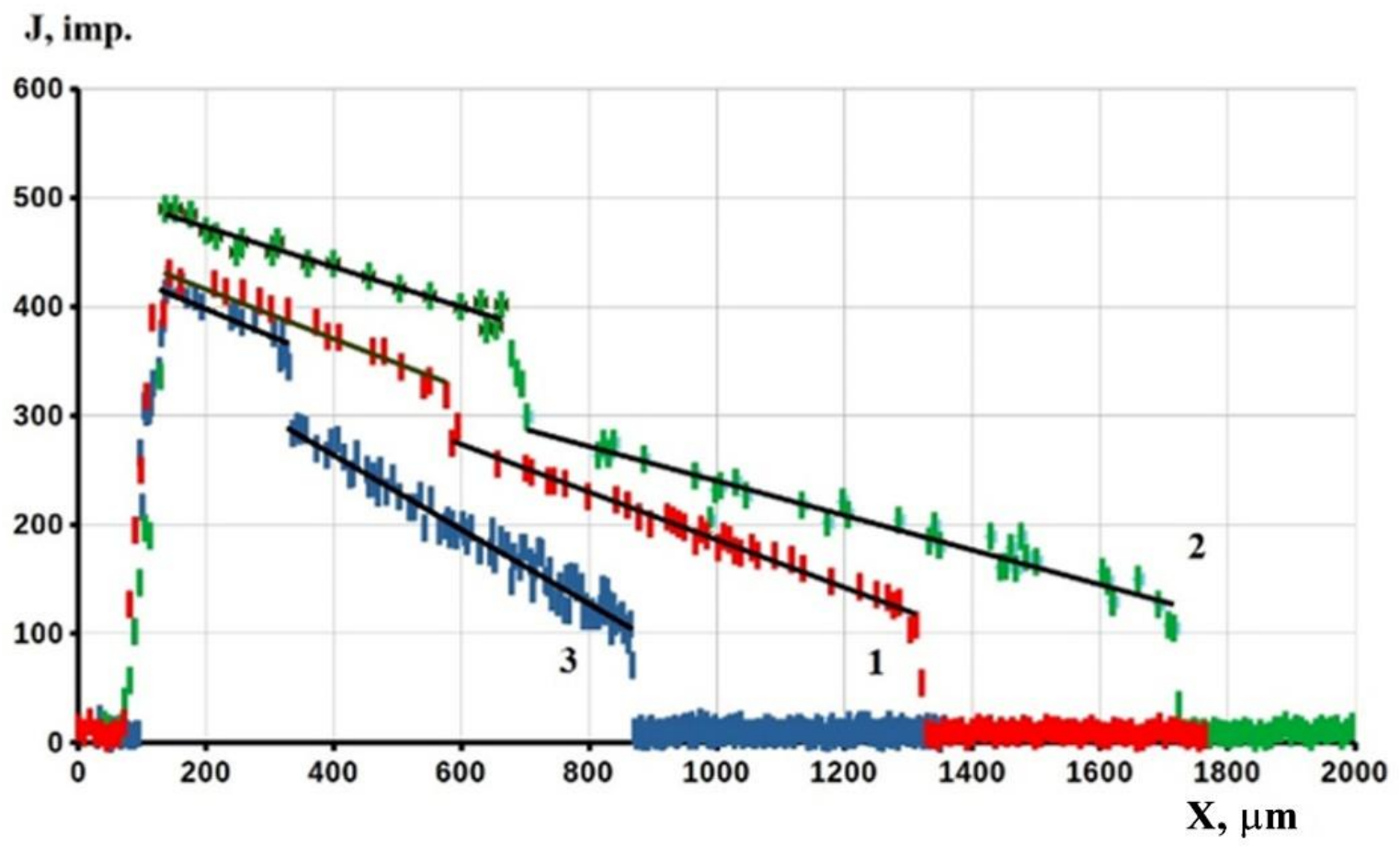

Figure 2. Diffusion profiles of phosphorus $P$ in the penetration of $60 \% \mathrm{H}_{3} \mathrm{PO}_{4}$ at $50^{\circ} \mathrm{C}$ for $1008 \mathrm{~h}$ into model epoxy materials based on the ED-20 resin (100 mass parts) modified with SKN-26-1A rubber (2.5 mass parts). The content of the amine-based TETA curing agent: 1-10 mass parts ( 1 stoichiometric amount); $2-10$ mass parts with addition of the RAO-20 amine-based plasticizing agent -2.5 mass parts (1 stoichiometric amount+amine); $3-8$ mass parts (0.8 stoichiometric amount).

Thus, the diffusion profiles of phosphoric acid qualitatively differ from those of hydrochloric, sulfuric, or organic acids. The main difference consists in the presence of a significantly larger diffusant concentration gradient in the penetration zone and indications of a 2-step shape. A likely reason is that phosphoric acid is weaker and polybasic; its plastifying action may also be of importance (Table 1).

Table 1. Comparative characteristics of inorganic acids.

\begin{tabular}{|c|c|c|c|c|c|}
\hline & Acid & Ionization stage & $P, K_{\mathbf{a}}$ & Molar volume $V_{\mathrm{m}}=M_{\mathrm{m}} / \rho, \mathrm{cm}^{3} / \mathrm{mol}$ & Source \\
\hline 1 & $\mathrm{HCl}$ & 1 & -7 & $24.8-30.7$ & \multirow{6}{*}{ [8] } \\
\hline \multirow{2}{*}{2} & \multirow{2}{*}{$\mathrm{H}_{2} \mathrm{SO}_{4}$} & 1 & -3 & \multirow{2}{*}{53.4} & \\
\hline & & 2 & 1.9 & & \\
\hline \multirow{3}{*}{3} & \multirow{3}{*}{$\mathrm{H}_{3} \mathrm{PO}_{4}$} & 1 & 2.12 & \multirow{3}{*}{58.2} & \\
\hline & & 2 & 7.20 & & \\
\hline & & 3 & $11.9-12.7$ & & \\
\hline
\end{tabular}


This table shows that:

- the degree of phosphoric acid dissociation at the first stage, $\mathrm{pKa}=2.12$, is significantly lower than that of monobasic hydrochloric acid, $\mathrm{pKa}=-7$, and even smaller than that of sulfuric acid at the second stage, $\mathrm{pKa}=1.9$. This implies that under comparable conditions more molecules will be in molecular form in the diffusion zone of phosphoric acid;

- since the molecular volume of the phosphoric acid molecule is larger, it is necessary to take into account the physical plastifying effect of acid in the diffusion zone upon binding of the acid, in addition to the chemical plastification of the matrix.

An important specific feature of the profiles of phosphoric acid distribution is the equality of concentration gradients in the surface (left) and bulk (right) diffusion zones. This implies that the diffusant distribution in the penetration zone is steady-state, and the total rate of acid anion transport should be determined by the diffusant drain rate due to the rapid binding of acid on the penetration boundary.

To explain the specific features of the phosphoric acid diffusion profile, one can also hypothesize that the ionic composition of phosphoric acid $\left(\mathrm{H}_{2} \mathrm{PO}_{4}^{-}, \mathrm{HPO}_{4}^{2-}\right.$, and $\left.\mathrm{PO}_{4}^{3-}\right)$ changes in the inner solution in the polymer upon $\mathrm{pH}$ variation.

\subsection{Fluorescent analysis of the reactions of mineral acids with the epoxy polymer}

It is known [6] that intermolecular donor-acceptor complexes can be formed in a solid polymer phase from molecules in the ground or excited energy states. As a result of charge transfer due to electron exchange (Lewis acids/bases) or proton exchange (Bronsted acids/bases), some of these complexes can luminesce.

Luminescence of these active centers occurs in the form of fluorescence to the ground state from singlet energy levels usually characteristic of the dimer complex or in the form of phosphorescence from triplet energy levels of both the complex itself and the molecules/groups it contains [6].

Photon or electron induced fluorescence and phosphorescence in epoxides is characterized [9-15] by wavelengths $\lambda=412,437,450,460,470,500,510,518,540,550$, 578,607 and $636 \mathrm{~nm}$ which the authors associate with various centers of epoxide oligomers and curing amine-based agents. The fluorescence of amine-cured epoxides under study was observed in the "blue" part of the spectrum with maxima at wavelengths of $\lambda=422,468$ and $502 \mathrm{~nm}$; in the "green" part, at 513, 540 and $574 \mathrm{~nm}$; and in the "red" part, at 590, 615 and $637 \mathrm{~nm}[1]$.

The dependence of epoxide fluorescence intensity on the amount of added aliphatic amine-based curing agent PEPA (Table 2) shows that the fluorescence intensity is enhanced with an increase in amine concentration.

It can be seen that the fluorescence enhancement in the systems under study is due to the accumulation of excess amounts of amino groups in the polymer matrix.

The duration of fluorescence of chromophore centers in epoxides [9-15], which ranges from milliseconds to nanoseconds, was not estimated in this study. Attention was focused 
on the estimation of the characteristic times of phosphorescence decay that attained $1-5 \mathrm{~s}$ in the systems we studied and depended on the composition and temperature of observation.

It can be seen that the fluorescence enhancement in the systems under study is due to the accumulation of excess amounts of amino groups in the polymer matrix.

The duration of fluorescence of chromophore centers in epoxides [9-15], which ranges from milliseconds to nanoseconds, was not estimated in this study. Attention was focused on the estimation of the characteristic times of phosphorescence decay that attained $1-5 \mathrm{~s}$ in the systems we studied and depended on the composition and temperature of observation.

Table 2. Fluorescence intensity $J / J_{\max }$ of ED-20 epoxy resin (100 mass parts) cured using aliphatic amine PEPA vs. its content Camine per 100 mass parts of ED-20. The wavelengths $\lambda$ are $502 \mathrm{~nm}$ (excitation at $360 \mathrm{~nm}$ ), $513 \mathrm{~nm}$ (excitation at $390 \mathrm{~nm}$ ), and $590 \mathrm{~nm}$ (excitation at $520 \mathrm{~nm}$ ).

\begin{tabular}{ccccc}
\hline & \multirow{2}{*}{$\begin{array}{c}\text { Curing agent, mass parts per } \\
\text { 100 mass parts of ED-20 }\end{array}$} & \multicolumn{2}{c}{ Fluorescence intensity $\boldsymbol{J} / \boldsymbol{J}_{\text {max }}$ for $\lambda_{\text {obs }} / \lambda_{\text {exc }}(\mathbf{n m})$} \\
\cline { 3 - 5 } & 8 & $\mathbf{5 0 2 / 3 6 0}$ & $\mathbf{5 1 3 / 3 9 0}$ & $\mathbf{5 9 0 / 5 2 0}$ \\
\hline 1 & 10 & 0.32 & 0.44 & 0.17 \\
2 & 12 & 0.64 & 0.61 & 0.51 \\
3 & 20 & 0.52 & 0.63 & 0.52 \\
4 & 1.00 & 1.00 & 1.00 \\
\hline
\end{tabular}

Epoxy phosphorescence was enhanced upon addition of a low-molecular carboxylated butadiene-acrylonitrile rubber to the compound; it is noteworthy that the plot of phosphorescence intensity on the rubber content passes through an extremum (Figure 3).

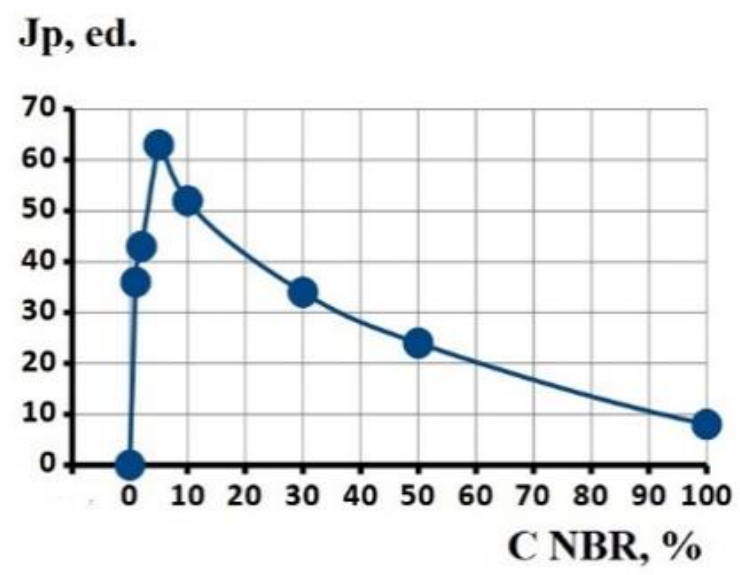

Figure 3. Concentration dependence at $25^{\circ} \mathrm{C}$ of the phosphorescence intensity of ED-20 epoxy resin cured with an aromatic amine ( $m$-phenylenediamine, MPDA) with addition of butadiene-acrylonitrile rubber SKN-26-1A with terminal carboxy groups.

The phosphorescence decay curve in the model epoxide materials that we studied is described by two exponents, as it was reported in [6], with the lifetimes $\tau_{1}=1.2 \mathrm{~s}$ and 
$\tau_{2}=3.4 \mathrm{~s}$ (Figure 4). The occurrence of two phosphorescence processes in amine-cured epoxides was also discovered in [16].

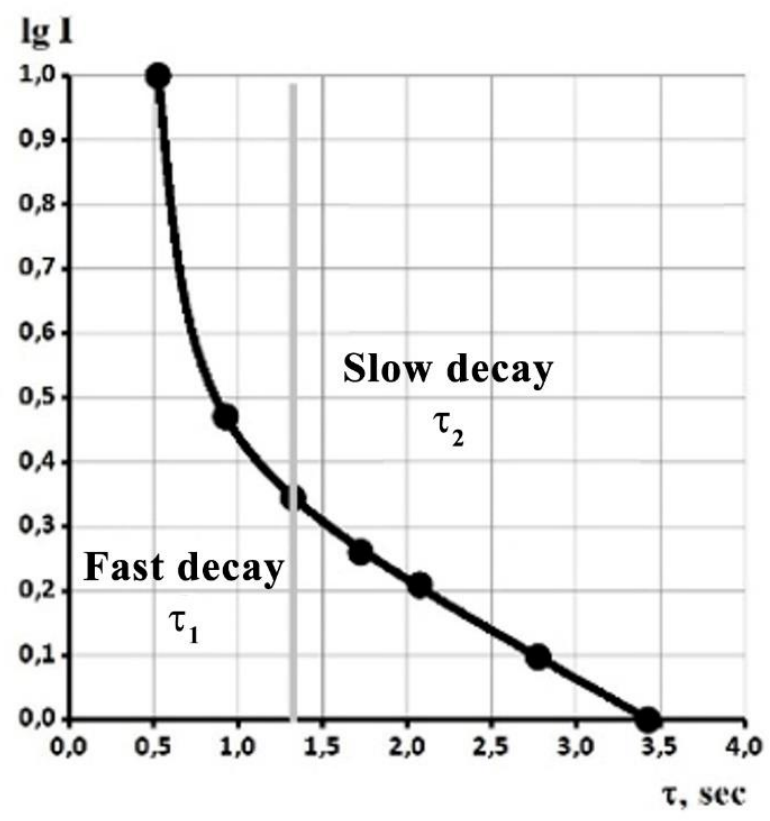

Figure 4. Kinetics of the phosphorescence decay of ED-20 epoxy resin cured with an aliphatic amine (TETA) with addition of SKN-26-1A butadiene-acrylonitrile rubber.

If phosphorescence in the systems we examine is excited by blue light $(\lambda=513 \mathrm{~nm})$, the decay with time constant $\tau_{1}$ is observed in the region of $\lambda_{1}=540 \mathrm{~nm}$, and that with $\tau_{2}$, as green-blue glow in the region of $\lambda_{2}=535 \mathrm{~nm}$ (Figure 4).

Of utmost importance for diffusion studies is the fact that upon penetration of chemically reactive substances, the luminescence intensity changes, while fluorescence can either be enhanced or quenched. Moreover, if the concentration of phosphorescence quenchers, in particular, some acid anions, is high, the phosphorescence intensity diminishes without changes in decay times $\tau_{1}$ and $\tau_{2}$; this corresponds [6] to a reduction in the quantum yield under static quenching of phosphorescence, similarly to fluorescence quenching. Of importance for this study is that both phosphorescence enhancement and quenching in the diffusion penetration region is observed in solutions of all the acids under study, i.e., $\mathrm{HCl}$, $\mathrm{H}_{2} \mathrm{SO}_{4}$ and $\mathrm{H}_{3} \mathrm{PO}_{4}$.

The process of intensity change is interpreted [6] as a sequential transformation of the forms of the chromophore center upon penetration of acid and water. However, since the composition of the fluorescence and phosphorescence centers of epoxy resins containing water and acids is very complex, their nature is not yet fully understood.

The complex character of the variation in fluorescence intensity $J$ along the acid diffusion coordinate $X$ for various spectral ranges $\lambda$ is illustrated by Figure 5, where the spectral and spatial distribution of optical fluorescence in the zone of penetration of $87 \%$ phosphoric acid into an epoxide polymer cured with an aromatic amine is displayed as an example. 


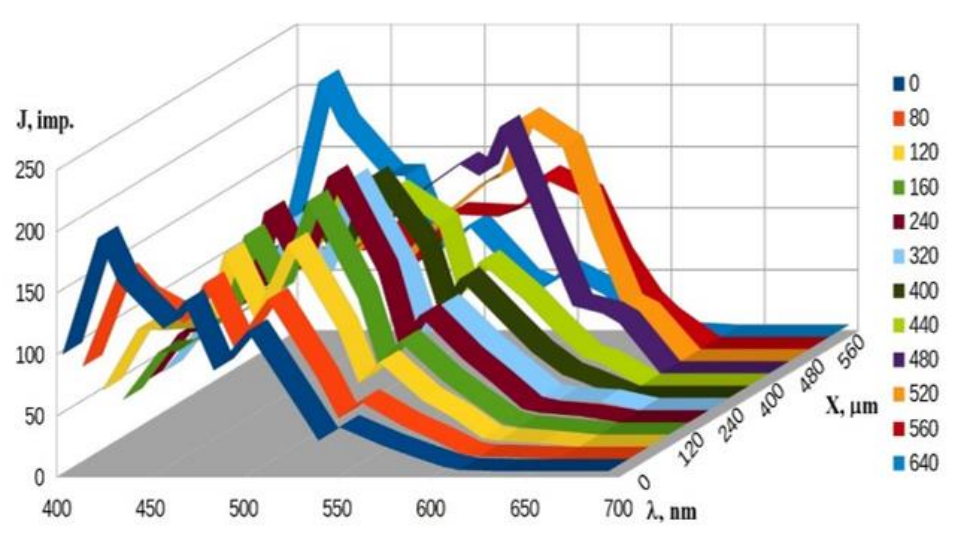

Figure 5. Spectral and spatial distribution of fluorescence upon penetration of $87 \% \mathrm{H}_{3} \mathrm{PO}_{4}$ at $70^{\circ} \mathrm{C}$ for $200 \mathrm{~h}$ in a model amine-cured epoxy material of the following composition: ED-20 100 mass parts, SKN-26-1A - 30 mass parts, and aromatic amine -13.5 mass parts.

The results of fluorescence spectroscopy, which correlate with those of IR spectroscopy [3], show that the main reactions of the epoxy resin matrix in contact with acids are determined by the reaction of diffusing anions with the amino groups of resin.

Thus, the studies conducted earlier [3] and analysis of reported luminescence phenomena in reactions of mineral and organic acid with amine-containing materials and coatings indicate that:

- observation of fluorescence and long-lasting phosphorescence of polymers with amino, carboxy, hydroxy, and nitrilo groups makes it possible to assume that the initial polymer contains several fluorescence centers, eximers/exiplexes that are formed by the complexes of amin and polar groups of modifying additives. The amino groups contained in the polymer may be either tertiary groups, which emerge in the case of a complete reaction between amino and epoxy groups, and secondary and residual primary groups in the case of excess amine or unavailability of amino or epoxy groups under the conditions of rapidly increasing viscosity of the system as it is cured;

- the penetrating anions of mineral acids decompose the fluorescing complexes formed by less-acid functional groups and, by forming acidoamides instead of hydroxylamines, nitriloamidines or carboxylamides, cause spectral shifts of fluorescence bands, an increase in fluorescence intensity, and phosphorescence quenching.

\subsection{Comparative fluorescence analysis of acid penetration}

Figure 6 below displays fluorescence microscopic images of the edge cleave of a polymer sample upon penetration of acids $\left(20 \% \mathrm{HCl}, 40 \% \mathrm{H}_{2} \mathrm{SO}_{4}\right.$, and $\left.60 \% \mathrm{H}_{3} \mathrm{PO}_{4}\right)$ in various spectral ranges of fluorescence excitation/observation; namely, UV (ultraviolet) 250-290 nm/ $330-400 \mathrm{~nm}, \mathrm{~V}$ (violet-blue) $395-415 \mathrm{~nm} / 420-500 \mathrm{~nm}, \mathrm{~B}$ (blue) $420-485 \mathrm{~nm} / 480-700 \mathrm{~nm}$, and $\mathrm{G}$ (green) $460-550 \mathrm{~nm} / 600-700 \mathrm{~nm}$. 


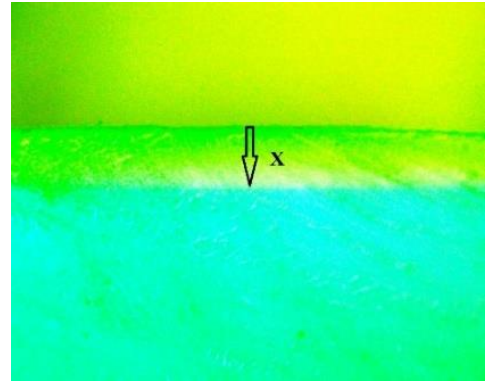

UV

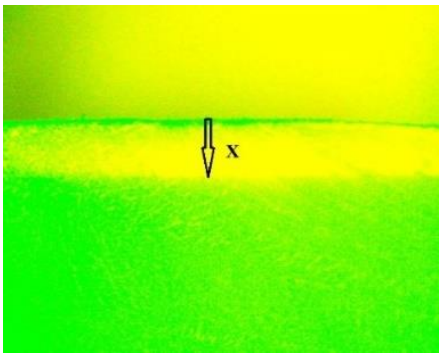

V

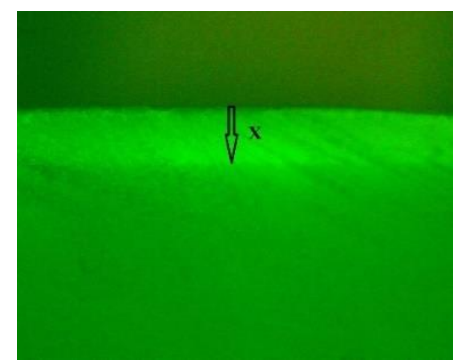

B

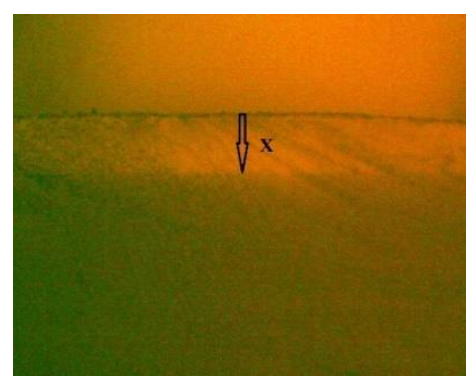

G

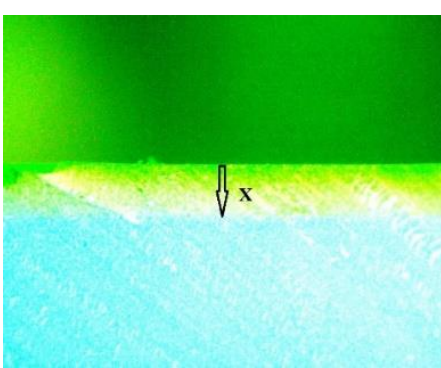

UV

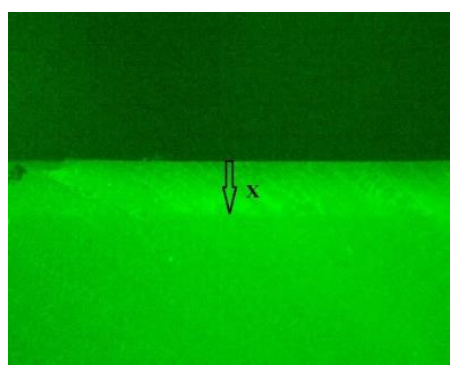

V

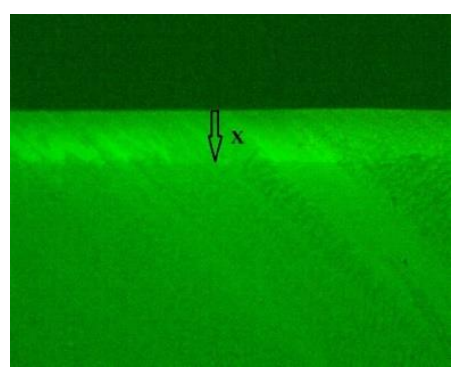

B

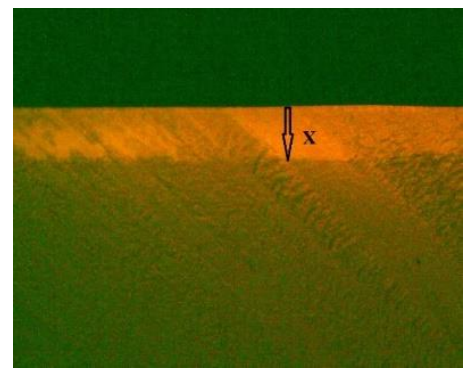

G

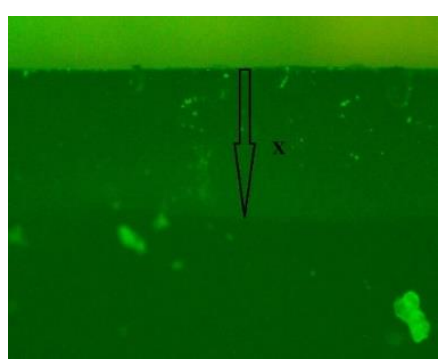

UV

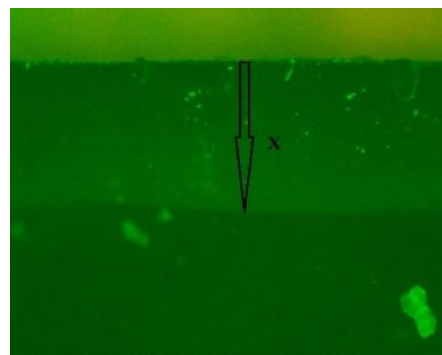

V

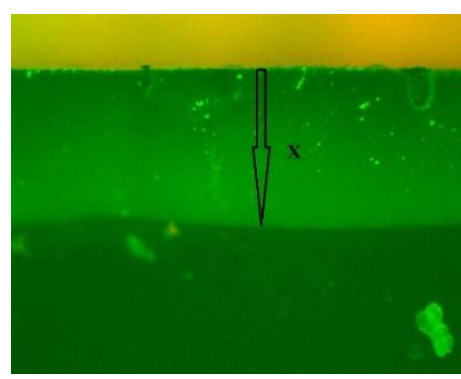

B

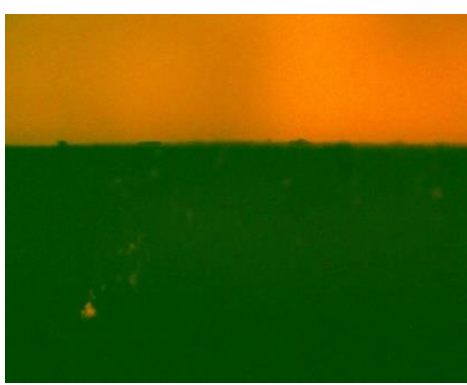

G

$60 \% \mathrm{H}_{3} \mathrm{PO}_{4}$

$20 \% \mathrm{HCl}$

$40 \% \mathrm{H}_{2} \mathrm{SO}_{4}$

Figure 6. Optical fluorescence images of the microscopic images of sample cleavage in the
zone of acid penetration at $50^{\circ} \mathrm{C}$ for $1008 \mathrm{~h}$ into a model amine-cured epoxy material (based on stoichiometry). Spectral bands: UV, V, B, and G. X is the depth of acid front penetration. The arrow shows the direction of acid diffusion. 
Analysis of phosphoric acid penetration depths measured using X-ray $\left(X_{\mathrm{R}}\right)$ and optical $\left(X_{\mathrm{F}}\right)$ fluorescence shows their good agreement (Table 3).

Table 3. Depths of penetration of $60 \% \mathrm{H}_{3} \mathrm{PO}_{4}$ at $50^{\circ} \mathrm{C}$ for $t=1008 \mathrm{~h}$ into model amine-cured epoxide materials detected using $X$-ray $\left(X_{\mathrm{R}}\right)$ and optical $\left(X_{\mathrm{F}}\right)$ fluorescence.

\begin{tabular}{|c|c|c|c|c|c|c|}
\hline \multirow{2}{*}{$\begin{array}{c}\text { Composition } \\
\text { no. }\end{array}$} & \multicolumn{4}{|c|}{ Content of component, mass parts } & \multicolumn{2}{|c|}{$\begin{array}{l}\text { Penetration depth } \\
\mu \mathrm{m}\end{array}$} \\
\hline & $\begin{array}{l}\text { Epoxy } \\
\text { resin } \\
\text { ED-20 }\end{array}$ & $\begin{array}{c}\text { Nitrile } \\
\text { rubber } \\
\text { SKN-26-1A }\end{array}$ & $\begin{array}{c}\text { Amine-based } \\
\text { curing agent } \\
\text { TETA }\end{array}$ & $\begin{array}{c}\text { Amine-containing } \\
\text { plastifier } \\
\text { RAO-20 }\end{array}$ & $X_{\mathrm{R}}$ & $X_{\mathrm{F}}$ \\
\hline 1 & 100 & 2.5 & 10 & - & 1250 & 1254 \\
\hline 2 & 100 & 2.5 & 10 & 2.5 & 1652 & 1657 \\
\hline 3 & 100 & 2.5 & 8 & - & 775 & 771 \\
\hline
\end{tabular}

The microscopic images displayed above show that, in the course of phosphoric acid penetration, its anions compete with the acid groups of the resin and displace them from luminescence centers, causing an enhancement of polymer fluorescence and quenching of phosphorescence.

The change in the fluorescence spectrum can be probably explained by the displacing effect of phosphoric acid and the destruction of existing and formation of new fluorescence centers. This can be estimated by comparing the strength of phosphoric acid anions and other reactive acid groups in epoxides (Table 4 ).

Table 4. Comparison of the strength of phosphoric acid anions and reactive acid groups in epoxides competing with phosphate anions in reactions with amine groups.

\begin{tabular}{ccccc}
\hline & Acid & Ionization stage & $\mathbf{p} \boldsymbol{K}_{\mathbf{a}}$ & Reference \\
\hline & & 1 & 2.12 & \\
1 & $\mathrm{H}_{3} \mathrm{PO}_{4}$ & 2 & 7.20 & {$[8]$} \\
& & 3 & $11.9-12.7$ & \\
\hline 2 & $-\mathrm{COOH}$ terminal carboxyl & 1 & $2.5-3.0$ & {$[6]$} \\
\hline 3 & $-\mathrm{COOH}$ carboxylic acids & 1 & $3.0-5.0$ & {$[8],[6]$} \\
\hline 4 & $-\mathrm{CN}$ & 1 & 9.1 & {$[8]$} \\
\hline 5 & - OH phenol & 1 & 9.89 & {$[8]$} \\
\hline 6 & $-\mathrm{OH}$ polyvinyl acetate & 1 & 12.8 & {$[17]$} \\
\hline
\end{tabular}

Table 4 shows that the $\mathrm{p} K_{\mathrm{a}}$ values of acid anions correspond to the $\mathrm{p} K_{\mathrm{a}}$ range of reactive polymer groups; the intermolecular complex of the resin amine group with the terminal carboxyl with $\mathrm{p} K_{\mathrm{a}}>2.5$ can be destructed by diffusing $\mathrm{H}_{2} \mathrm{PO}_{4}^{-}$with $\mathrm{p} K_{\mathrm{a}} 2.12$; nitrile and 
hydroxy groups with $\mathrm{p} K_{\mathrm{a}}>9$ can be displaced from the luminescence centers already by the anion of the second dissociation stage of $\mathrm{HPO}_{4}^{2-}$ with $\mathrm{p} K_{\mathrm{a}} 7.2$; even the $\mathrm{PO}_{4}^{3-}$ anion at the third dissociation stage with $\mathrm{p} K_{\mathrm{a}} 12.7$ can compete with the hydroxyl with $\mathrm{p} K_{\mathrm{a}} 12.8$.

\section{A model of phosphoric acid diffusion into polymer coatings}

The results presented above allow us to make the conclusion that, in the case of polybasic and comparatively weak phosphoric acid, the diffusion picture of the motion of the maximum penetration front $X_{\max }$ is qualitatively similar to that of other acids, i.e., both monobasic hydrochloric and organic acids and dibasic sulfuric acid (until it begins to manifest oxidizing properties).

A model has been formulated earlier [3] for the diffusion of hydrochloric and sulfuric acids into polymer materials. It is described by Equation 1. The model assumes the fast irreversible binding of an acid on the reactive groups of a polymer and the existence in the polymer of acid/water associates with a constant composition that does not depend on the composition of the external solution.

$$
\lambda^{2}=\frac{2 k P_{\mathrm{ha}}}{E_{\mathrm{R}}} D_{0} \exp \left[-\frac{E_{\mathrm{a}}}{R T}\right]\left[\left(P_{\mathrm{W}} / P_{\mathrm{W}}^{0}\right)^{n} \cdot\left(P_{\mathrm{ha}} / P_{\mathrm{ha}}^{0}\right)^{m}\right]
$$

Where $\lambda$ is the rate of the acid front penetration, $k$ is the Boltzmann constant, $P_{\text {ha }}$ is the partial pressure of acid vapors, $P_{\mathrm{W}}$ is the partial pressure of water vapors, $P_{\mathrm{W}}^{0}$ and $P_{\mathrm{ha}}^{0}$ is the pressure of water and acid vapors over individual diffusants, $n$ is the number of water molecules in the acid/water associates in the polymer, $m$ is the number of acid molecules in the acid/water associates in the polymer, $E_{\mathrm{R}}$ is the concentration of reactive groups in the polymer, $D_{0}$ is the diffusion coefficient, $E_{\mathrm{a}}$ is the diffusion activation energy, $R$ is the universal gas constant, and $T$ is the temperature.

The model predicts a linear dependence of the penetration rate $\lambda=X_{\max } / \sqrt{t}$ on the ratio of partial pressures of water vapors $P_{\mathrm{W}}$ and acid vapors $P_{\text {ha }}$ over a diffusing solution plotted in the $2 \cdot \lg \lambda \sim\left[\left(P_{\mathrm{W}} / P_{W}^{0}\right)^{n} \cdot\left(P_{\mathrm{ha}} / P_{\mathrm{ha}}^{0}\right)^{m}\right]$ coordinates.

The penetration rate $\lambda$ of phosphoric acid can be easily determined experimentally since it is can be efficiently detected by all techniques, namely, local X-ray spectral analysis [7], microscopic observation of the change in fluorescence color of a drop indicator [3], and detection of changes in the fluorescence color of the polymer matrix itself under the effect of phosphoric acid (Figure 7). 


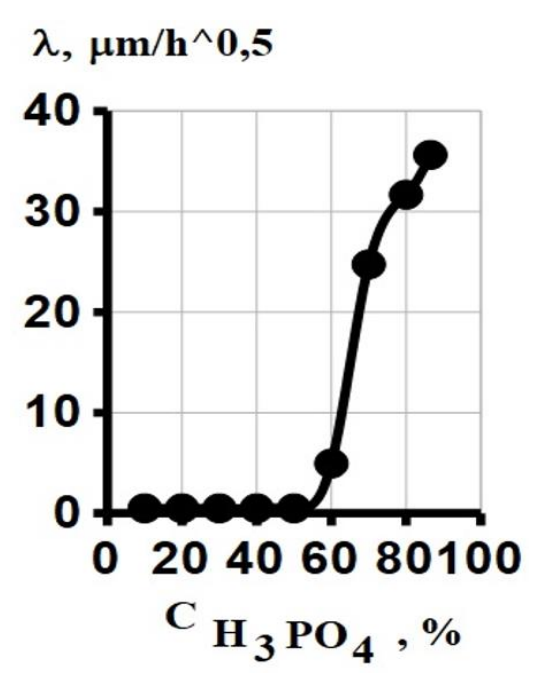

Figure 7. Concentration plot of the penetration rate constant $\lambda\left(\mu \mathrm{m} / \mathrm{h}^{0.5}\right)$ of phosphoric acid solutions into a model amine-cured epoxide with the following composition: ED-20 100 mass parts, SKN-26-1A - 30 mass parts, and MPDA - 13.5 mass parts (based on stoichiometry) at $+70^{\circ} \mathrm{C}$.

However, unlike highly volatile $(\mathrm{HCl})$ and low-volatile $\left(\mathrm{H}_{2} \mathrm{SO}_{4}\right)$ acids, applying this model to phosphoric acid encounters a problem that, due to its non-volatility, it is difficult to determine the partial pressure of its vapors over solutions, and reliable reference data for $P_{\text {ha }}$ are missing. However, data on water activity $\left(P_{\mathrm{w}} / P_{\mathrm{w}}{ }^{0}\right)$ over phosphoric acid solutions are available [18]; this enables the calculation of the thermodynamic activity of the acid using the change in the water activity in the acid solution according to the well-known GibbsDuhem Equation:

$$
\sum n_{\mathrm{i}} \cdot d \mu_{\mathrm{i}}=0
$$

The water vapor pressure as a function of solution composition [18] at temperatures of $60^{\circ} \mathrm{C}$ and $80^{\circ} \mathrm{C}$ is shown below (Figure 8).

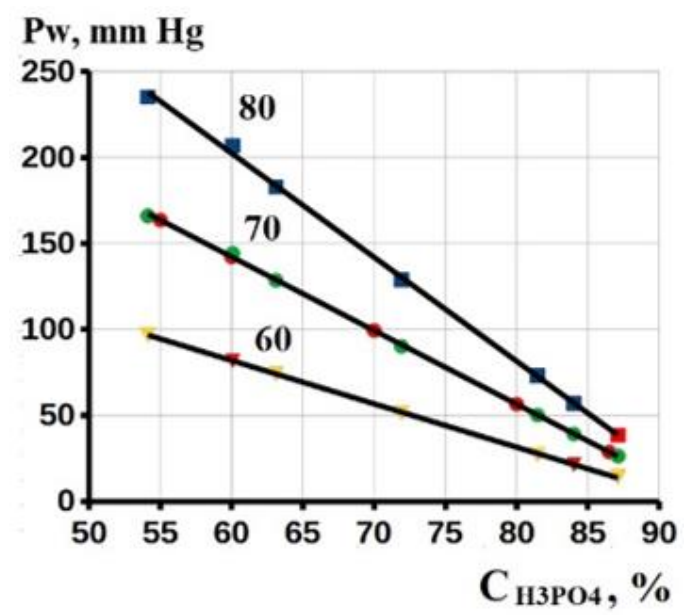

Figure 8. Concentration dependence of the partial water vapor pressure over phosphoric acid solutions in the concentration range of $55-87 \%$ at 60,70 , and $80^{\circ} \mathrm{C}$. 
Interpolation and extrapolation of linear dependences for temperatures of $60^{\circ} \mathrm{C}$ and $80^{\circ} \mathrm{C}$ can be used to obtain the $P_{\mathrm{w}}$ values also for missing reference concentrations at $70^{\circ} \mathrm{C}$.

The concentration dependence of the change in the chemical potential of water in a phosphoric acid solution at $70^{\circ} \mathrm{C}$ calculated using the $P_{\mathrm{W}}^{70}$ values obtained is presented below (Table 5).

Table 5. Calculated concentration dependence of the change in the chemical potential of water in a phosphoric acid solution at $70^{\circ} \mathrm{C}$. Bold values correspond to the solutions studied experimentally.

\begin{tabular}{|c|c|c|c|c|c|c|}
\hline $\begin{array}{c}\text { Mass } \\
\text { fraction of } \\
\text { acid } \omega_{\mathrm{h}}, \%\end{array}$ & $\begin{array}{c}\text { Mass } \\
\text { fraction } \\
\text { of water } \\
\omega \mathrm{w}, \%\end{array}$ & $\begin{array}{c}\text { Molar fraction } \\
\text { of water } \\
\varphi_{1}=x_{\mathrm{w}}= \\
\left(\omega_{\mathrm{w}} / M_{\mathrm{w}}\right) / \Sigma\left(\omega_{\mathrm{i}} /\right. \\
\left.M_{\mathrm{i}}\right)\end{array}$ & $\begin{array}{c}\text { Water } \\
\text { pressure } \\
\text { over acid } \\
\text { solution } \\
P_{\mathrm{w}^{70}}, \mathbf{m m H g}\end{array}$ & $\begin{array}{c}\text { Water } \\
\text { activity } \\
\boldsymbol{a}_{\mathrm{w}}=\boldsymbol{P}_{\mathrm{w}} / \\
\boldsymbol{P}_{\mathrm{w}^{0}}\end{array}$ & $\ln \left(a_{\mathrm{w}}\right)$ & $\begin{array}{c}\text { Change in the } \\
\text { chemical potential } \\
\text { of water } \\
\Delta \mu_{\mathrm{w}}=-R T \cdot \ln \left(a_{\mathrm{w}}\right), \\
\mathrm{J} / \mathrm{mol}\end{array}$ \\
\hline $\mathrm{H}_{3} \mathrm{PO}_{4}$ & \multicolumn{6}{|c|}{$\mathrm{H}_{2} \mathrm{O}$} \\
\hline 0.0 & 100.0 & 1.000 & 252.24 & 1.000 & 0.000 & 0 \\
\hline 54.1 & 45.9 & 0.822 & 166.02 & 0.658 & -0.418 & 1193 \\
\hline 55.0 & 45.0 & 0.817 & 163.60 & 0.649 & -0.433 & 1235 \\
\hline 60.0 & 40.0 & 0.784 & 142.18 & 0.564 & -0.573 & 1635 \\
\hline 70.0 & 30.0 & 0.700 & 99.36 & 0.394 & -0.932 & 2657 \\
\hline 80.0 & 20.0 & 0.576 & 56.54 & 0.224 & -1.495 & 4264 \\
\hline 86.5 & 13.5 & 0.459 & 28.71 & 0.114 & -2.173 & 6197 \\
\hline 87.1 & 12.9 & 0.446 & 26.42 & 0.105 & -2.256 & 6434 \\
\hline
\end{tabular}

The determination of the chemical potential of water (Table 5) for experimental solutions makes it possible to calculate, with an accuracy to a constant $C$, the corresponding chemical potential of the acid using the Gibbs-Duhem Equation:

$$
\mu_{\mathrm{h}}\left(x_{\mathrm{h}}^{\prime}\right)-\mu_{\mathrm{h}}\left(x_{\mathrm{h}}^{\prime \prime}\right)=\int_{\mu_{\mathrm{W}}\left(x_{\mathrm{h}}^{\prime \prime}\right)}^{\mu_{\mathrm{W}}\left(x_{\mathrm{h}}^{\prime}\right)}-\frac{x_{\mathrm{W}}}{x_{\mathrm{h}}}\left(d \mu_{\mathrm{W}}\right)+c
$$

The constant $C$ can be determined using the requirement that the equality ( $\left.\Delta G_{\text {mix }}=\Delta \mu_{\mathrm{h}}=\Delta \mu_{\mathrm{W}}\right)$ should be fulfilled in the vicinity of the extremum of the Gibbs free energy of mixing, which makes it possible to apply the iteration method to find the desired value of $C$ (Figure 9). 


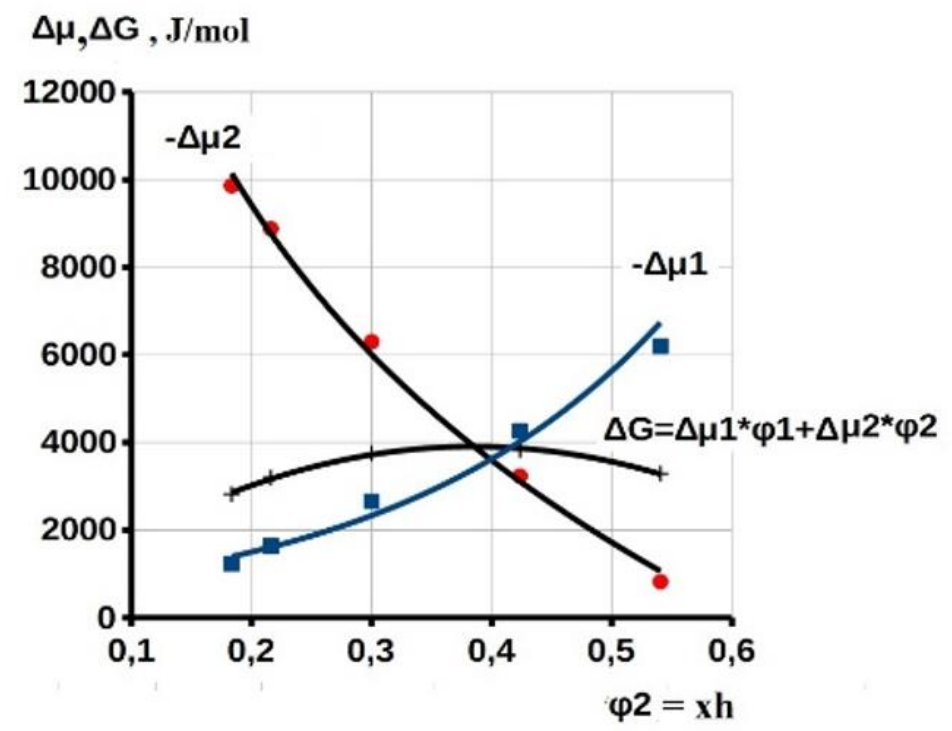

Figure 9. Concentration plot of changes in the chemical potentials of water, $-\Delta \mu_{\mathrm{w}}$ (1); phosphoric acid, $-\Delta \mu_{\mathrm{h}}$ (2); and Gibbs free energy of mixing $\Delta G$ for a $\mathrm{H}_{3} \mathrm{PO}_{4}$ solution (3).

The correctness of the calculation is confirmed by the fact that all the three dependences, $\Delta G_{\text {mix }}, \Delta \mu_{\mathrm{h}}, \Delta \mu_{\mathrm{W}}$, intersect at a single point at $C=-100 \mathrm{~J} / \mathrm{mol}$, and that the intersection point of the partial free energies of mixing (at a concentration value of about 0.4 ) coincides with the single intersection point of the partial molar enthalpies of water and acid with the excess enthalpy of the phosphoric acid solution of the same concentration [19].

The calculated values of the chemical potential of water, $\Delta \mu_{\mathrm{h}}$, can be used to determine the change in the activity and calculate the reduced activity of the diffusing inner solution $\left[\left(P_{\mathrm{W}} / P_{\mathrm{W}}^{0}\right)^{n} \cdot\left(P_{\mathrm{ha}} / P_{\mathrm{ha}}^{0}\right)^{m}\right]$ (Equation 1$)$ provided that information about the inner hydrate composition is available.

It has been shown for hydrochloric and sulfuric acids that the model of diffusion hydrates with constant composition $(n / m=$ const $)$ is the most adequate for the diffusion of acids into closely cross-linked thermoset plastics. For phosphoric acid, the sought-for value of $n$ can be independently estimated using published data: hydration numbers for the phosphate anion fall in the ranges of 7-10 for $\mathrm{H}_{2} \mathrm{PO}_{4}^{-}$[20], [21]; 7-13 for $\mathrm{HPO}_{4}^{2-}$ [22]; and 10-18 for $\mathrm{PO}_{4}^{3-}$ [21], [22]; the average value is in the range of 10-11.

Our calculations have shown (Figure 10) that the agreement between experimental data and the theoretical dependence is the best $\left(R^{2}=0.9986\right)$ for the values of $n=10.5$ and $m=1$, i.e., for the hydrate consisting of 10-11 water molecules per phosphoric acid molecule. 


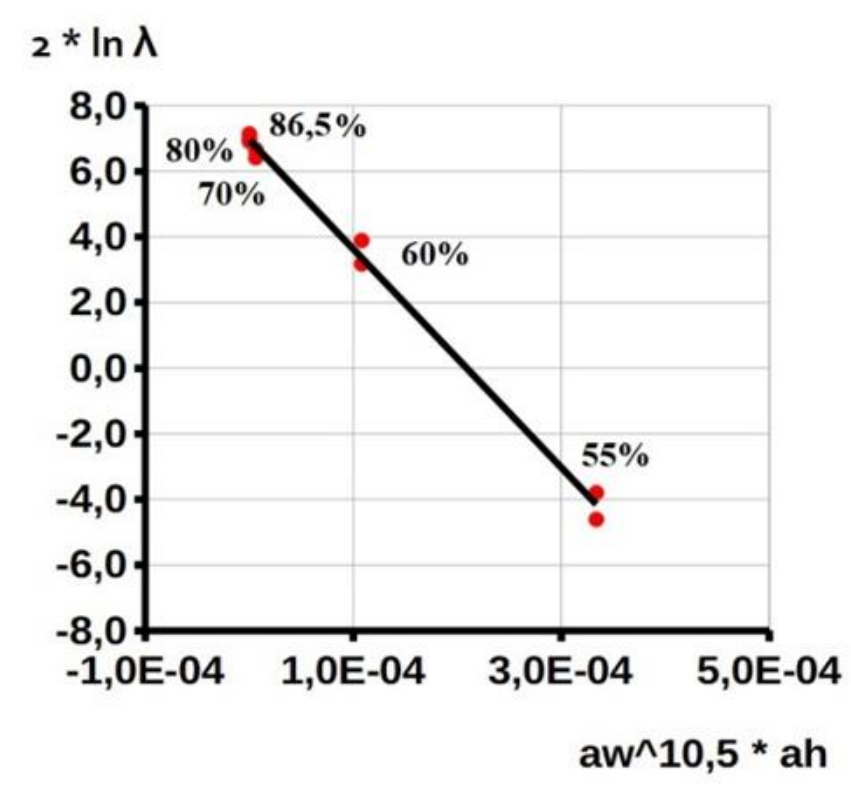

Figure 10. Logarithmic plot of the rate of bidirectional penetration of phosphoric acid solutions $\lambda v s$. the composition of water/acid hydrates, $n / m$, that diffuse into a model aminecured epoxide with the composition ED-20-100 mass parts, SKN-26-1A-30 mass parts, and MPDA-13.5 mass parts (based on stoichiometry) in a constant composition model with $n=10.5, \mathrm{~m}=1$, and $R^{2}=0.9986$.

To summarize, it has been shown that the diffusion model of constant composition hydrates with $n=10-11$ correctly $\left(R^{2}=0.9986\right.$ for 5 concentrations and 10 experimental values on the straight line) describes the bidirectional penetration of phosphoric acid solutions with concentrations of $54-87 \%$ in the model under consideration.

Regarding the practical cases of corrosion, the use of the diffusion model in combination with the calculation of the chemical potential of non-volatile electrolytes based on the Gibbs-Duhem equation makes it possible to significantly reduce the amount of diffusion studies and simplify the prediction of the impermeability time of coating materials in highly corrosive media.

\section{References}

1. V.A. Golovin and A.B. Il'in, Composite protective coatings. Resistance to acid penetration of coatings based on epoxy resins, Int. J. Corros. Scale Inhib., 2020, 9, 1530-1549 doi: 10.17675/2305-6894-2020-9-4-22

2. B.V. Salas, M.S. Wiener and J.R.S. Martinez, Phosphoric Acid Industry: Problems and Solutions, IntechOpen, 2017. doi: 10.5772/intechopen.70031

3. V.A. Golovin and A.B. Il'in, Diffusion of highly corrosive media (HCM) into protective polymer coating materials, Int. J. Corros. Scale Inhib., 2020, 9, 1329-1366. doi: 10.17675/2305-6894-2020-9-4-8

4. V.A. Golovin, A.B. Ilyin, A.D. Aliev, V.A. Shchelkov and V.A. Rabinkov, A study on the desorption of phosphonic acids, corrosion inhibitor precursors, from polymer 
microcapsules, Int. J. Corros. Scale Inhib., 2018, 7, 165-174. doi: 10.17675/2305-68942018-7-2-4

5. V.A. Golovin, A.B. Il'in and A.D. Aliev, Diffusion of phosphonic scale inhibitors in epoxy matrices, Mezhdunarodnyi nauchno-issledovatel'skii zhurnal, 2018, 4, 92-96. doi: $10.18454 /$ IRJ.2227-6017

6. E.A. Permyakov, Method of own protein luminescence, Moscow, Nauka, 2003, pp. 54-80 (in Russian).

7. A.E. Chalykh, A.D. Aliev and A.E. Rubtsov, Electron probe microanalysis in polymer studies, Moscow, Nauka, 1990 (in Russian).

8. A.V.Zinchenko, S.G. Izotova, A.V. Rumyantsev, S.A. Simonova, M.Y. Skripkin and A.A. Slobodov, New reference book for chemists and technologists. Chemical equilibrium. Properties of solutions, St. Petersburg, ANO NPO "Professional", 2004, pp. 998 (in Russian).

9. V. Griseri, L.A. Dissado, J.C. Fothergill, G. Teyssedre and C. Laurent, Space charge induced luminescence in epoxy resin, 4th International Conference on Electric Charge in Solid Insulators (CSC4), 2-6 July 2001, pp. 189-192. Link: https://www.researchgate.net/publication/48183009_Space_Charge_Induced_Lumines cence_in_Epoxy_Resin

10. S.C. Tjong and Y.-W. Mai, Physical Properties and Applications of Polymer Nanocomposites, Elsevier, 2010, p. 936.

11. Y. Yang, Y.-Q. Li, S.-Y. Fu and H.-M. Xiao, Transparent and Light-Emitting Epoxy Nanocomposites Containing $\mathrm{ZnO}$ Quantum Dots as Encapsulating Materials for Solid State Lighting, The Journal of Physical Chemistry, 2008, 112, 10553-10558. doi: 10.1021/jp802111q

12. J.C. Song and C.S.P. Sung, Room-Temperature Phosphorescence Studies of Epoxy Resin Cured by an Aromatic Diamine, Macromolecules, 1995, 28, 5581-5584. doi: $\underline{10.1021 / \mathrm{ma} 00120 \mathrm{a} 024}$

13. Luminescence techniques in solid state polymer research, Ed. L. Zlatekevitch, Marcel Dekker Inc, New York, 1989.

14. R. Toivola, S.-H. Jang, D. Mannikko, S. Stoll, A.K-Y. Jen and B.D. Flinn Photochemical changes in absorption and fluorescence of DDM-containing epoxies, Polymer, 2018, 142, 11-22. doi: 10.1016/j.polymer.2018.03.015

15. L. Hou, Y. Wu, J. Xiao, B. Guo and Y. Zong, Colored effects and mechanism in DDMcured epoxy after $170 \mathrm{keV}$ vacuum electron irradiation, Nucl. Instrum. Methods Phys. Res., Sect. B, 2019, 439, 1-6. doi: 10.1016/j.nimb.2018.11.002

16. O. Gallot-lavallée, G. Teyssedre, C. Laurent and S. Rowe, Identification of photoluminescence features of an epoxy resin based on components features and curing effects, Polymer, 2005, 46, 2722-2731. doi: 10.1016/j.polymer.2005.02.003

17. N.B. Sheiko, S.V. Myakin, A.G. Rodionov and M.M. Sychev, Vibration-absorbing composites based on polyvinylacetate and activated fillers, Proceedings of scientific 
conference dedicated to the $185^{\text {th }}$ anniversary of establishment of the Saint Petersburg technological institute (technical university), Saint Petersburg, 2013, p. 414 (in Russian). 18. M.E. Pozin, B.A. Kopylev, G.V. Bel'chenko and L.Ya. Tereshchenko, Calculations in technology of inorganic compounds, Ed. M.E. Pozin, $2^{\text {nd }}$ Ed., Leningrad, Khimiya, 1977, pp. 627 (in Russian).

19. S.P. Kochetkov, N.N. Smirnov and A.P. Il'in, Concentrating and purification of extraction phosphoric acid: Monograph, Ivanovo state university of chemistry and technology, Ivanovo, 2007, p. 53 (in Russian). ISBN 5-9616-0212-5

20. E. Tang, D.D. Tommaso, N. H. Leeuw, J. Chem. Phys., 2009, 130, 234-502. doi: $10.1063 / 1.3143952$

22. Y. Koga, T. Kondo, Y. Miyazaki, A. Inaba, J. Solution Chem., 2012, 41, 1388-1400.

23. P.E. Mason, J.M. Cruickshank, G.W. Neilson, P. Buchanan, Phys. Chem., 2003, 5, 4686-4690. doi: $\underline{10.1039 / \mathrm{b} 306344 \mathrm{e}}$ 